\title{
Evaluation of Antimicrobial Properties of Two Different Extracts of Juglans regia Tree Bark and Search for Their Compounds Using Gas Chromatography-Mass Spectrum
}

\author{
Ismet Ara ${ }^{1}$, M. M. A. Shinwari ${ }^{1}$, S. A. Rashed ${ }^{1}$ \& M. A. Bakir ${ }^{1}$ \\ ${ }^{1}$ Department of Botany and Microbiology, College of Science, King Saud University, Riyadh, Kingdom of \\ Saudi Arabia \\ Correspondence: Ismet Ara, Department of Botany and Microbiology, College of Science, King Saud University, \\ P. O. Box 22452, Riyadh 11495, Kingdom of Saudi Arabia. Tel: 966-1478-9585, Ext. 1639. E-mail: \\ drmoonismet@gmail.com, iara@ksu.edu.sa
}

Received: June 21, 2012 Accepted: March 1, 2013 Online Published: March 13, 2013

doi:10.5539/ijb.v5n2p92 URL: http://dx.doi.org/10.5539/ijb.v5n2p92

\begin{abstract}
Two extract from the walnut tree bark (Juglans regia) were investigated for antimicrobial activities against seven human pathogens such as: Bacillus subtilis ATCC 6633, Staphylococcus aureus ATCC 25923, salmonella suis ATCC 13076, Pseudomonas aeruginosa ATCC 27583, Escherichia coli ATCC 25922 and Shigella sonnei ATCC 11060 and one was human pathogenic fungus: Candida albicans ATCC 10231. In this study, methanol was used as an extraction solvent, and bioactivity screening was done by agar well diffusion method. The bark extract in both samples showed strong activities against almost all the pathogenic microorganisms. Furthermore, the purified crude extract of the two samples has been analyzed using gas chromatography-mass spectrometry (GC-MS). Results indicated that the main component in the crude extract for bark sample 1 (MHO) was cyclobutanol (91.7\%) and for bark sample 2 (MHC) was 1, 3-dioxolane, 2, 4, 5-trimethyl (92.9\%). In both extracts cyclobutanol was present in high percentage (91.7\%). Further, 4h-pyran-4-one,2,3-dihydro-3,-dihydroxy-6-methyl; 1,3-dioxolane-4-methanol,2,2-dimethyl; 1,6,3,4-dianhydro-2-deoxy-beta-d-lyxo-hexopyranose; cyclopropyl carbinol; 2-heptanamine,5-methyl-; pyrimidine-2,4(1h,3h)-dione,5-amino-6-nitroso; alanine; butanenitrile,2,3-dioxo-,dioxime,o,o-diacetyl; (r)-(-)-2-amino-1-propanol and benzaldehyde,4-ethoxy were present in both bark extracts as $80-89 \%$. Moreover, ethanamine,2-propoxy; 2-isopropoxyethylamine; (r)-(-)-2,2-dimethyl-1,3-dioxolane-4-methanol; 3,4-furandiol, tetrahydro-,cis; glycerin; eicosanoic acid; pentadecanoic acid; 1-octadecanamin,n-methyl and (s)-(+)-1-cyclohexylethylamine appeared in bark sample 1 as $80-91 \%$, while the compounds 1,3-dioxolane,2,4,5-trimethyl; 11-tridecen-1-ol; hexadecanal; 4-tridecene,(z); 2-undecene,(e); 4-tetradecene,(z); acetic acid, trifluoro-, decyl ester; 2-hydroxy-3,5-dimethylcyclopent-2-en-1-one and d-glycero-d-tallo-heptose were present in bark sample 2 as $80-92 \%$.
\end{abstract}

Keywords: antibacterial activity, human pathogenic bacteria and yeast, agar well diffusion method, metabolites, methanol extraction, Juglans regia, GC-MS analysis

\section{Introduction}

Over the past few decades, there has been much interest in natural products as sources of new antimicrobial agents. Different extracts from traditional medicinal plants have been tested. Many reports show the effect of traditional herbs against microorganisms. As a result, plants have become one of the bases of modern medicine (Evans et al., 2002). The increased resistance to currently available antibiotics and the problems presented by antimicrobial agents added in food and public's pressure on the food industry to avoid chemical preservatives are the main factors justifying the search and development of new antimicrobial agents, especially those of natural origin (Rauha et al., 2000; Proestos et al., 2005).

Persian walnut (Juglans regia) tree (Figure 1) is found almost everywhere throughout the world such as Japan, China, Pakistan, Southern Asia, India, Turkey, South Eastern Europe, Carpathian Mountains of Poland, Eastern and Southern parts of the United States, Mexico, Central America, Colombia and Argentina (McGranahan et al., 1998; McGranahan \& Leslie, 1990). This species is naturally distributed from East Turkey through North of Iran, 
Afghanistan, Pakistan, mountains of Nepal and central Asia (McGranahan et al., 1998). Afghanistan (Figure 2), with its various eco-geographical regions, is one of the major centers for the Persian walnut diversity. Native walnut populations are widely present in Afghanistan and are found as scattered individuals or groups of several trees in the borders of agricultural lands, orchards or by the rivers, usually close to human settlements (Fernandez-lopez et al., 2003).
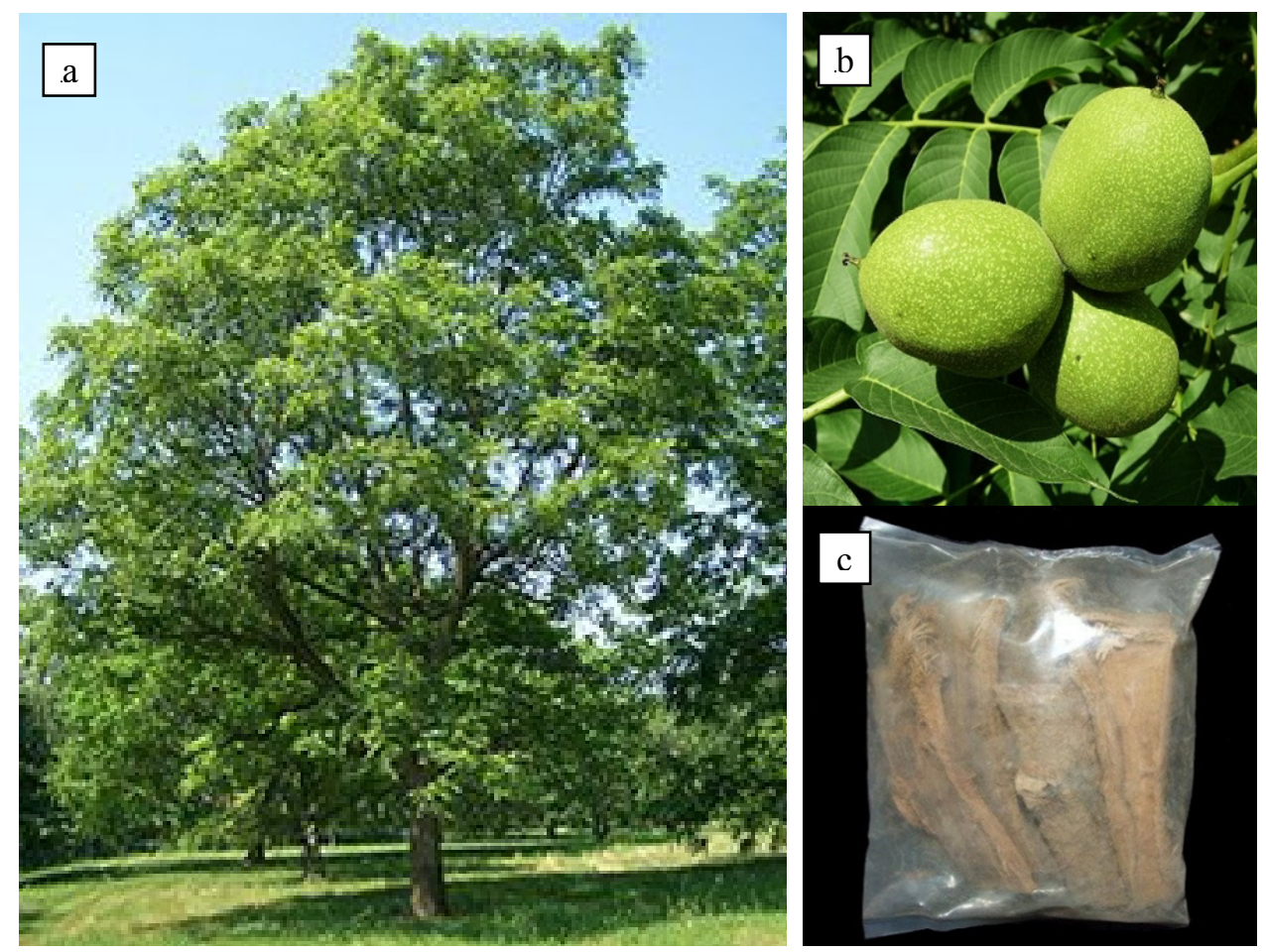

Figure 1. a. Persian walnut tree (Juglans regia); b. Fruit with green nuts; c. Dry barks

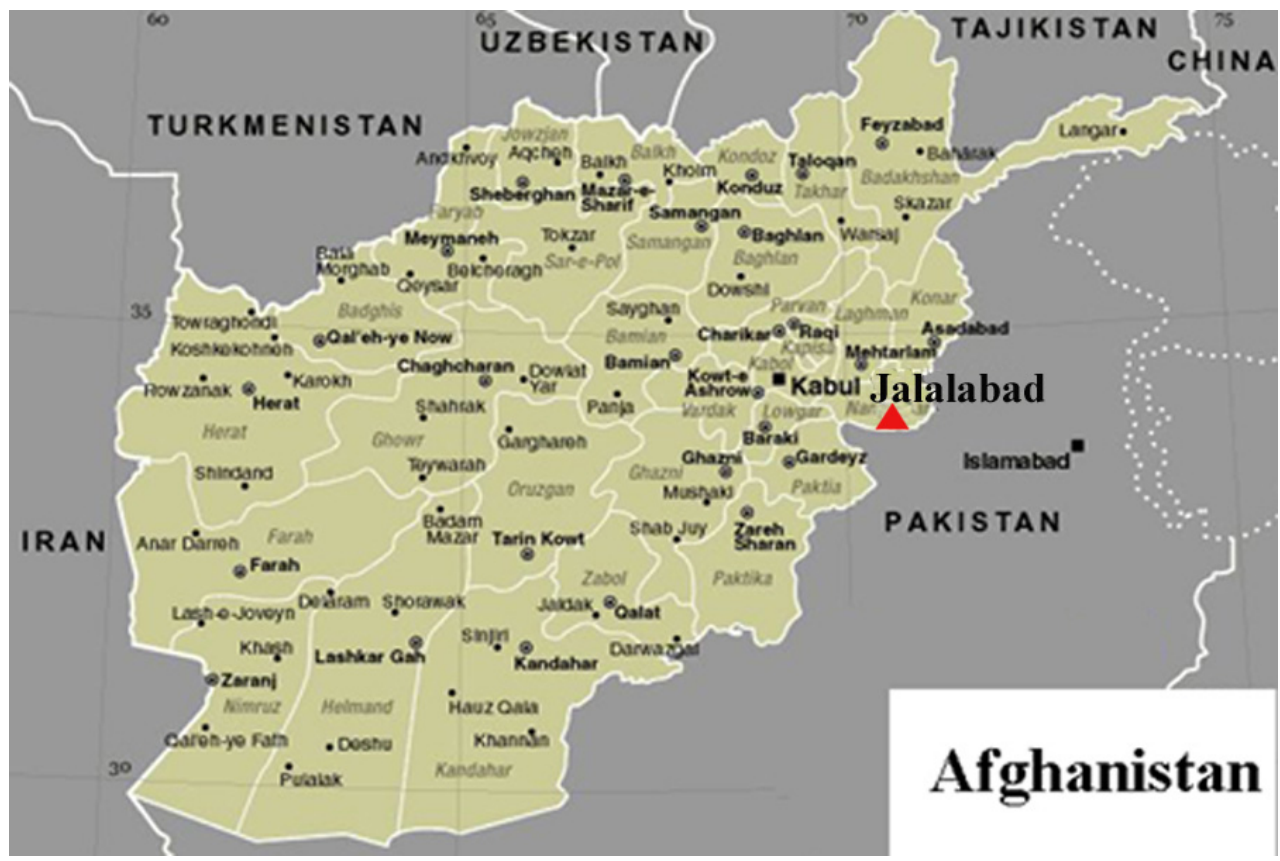

Figure 2. Afghanistan map showing the sampling region Jalalabad (red arrow) (MHO) 
The nuts are very popular and are largely consumed as a part of the diet. Nevertheless, not only seeds are used but also shells, bark, green husks and leaves in the cosmetic and pharmaceutical industries (Oliveira et al., 2008). Several studies suggest that regular consumption of walnut may have useful effects against oxidative stress mediated diseases such as cardiovascular diseases and cancer. Antiradical and antibacterial activities have also been recently described for different $J$. regia cultivars (Almeida et al., 2008). Recently, the chemical composition, antioxidant potential and antimicrobial activity have been studied in six walnuts (J. regia.) cultivars (cv. Franquette, Lara, Marbot, Mayette, Mellanaise and Parisienne) produced in Portugal (Pereira et al., 2007).

In Afghanistan, more than half of the population is using J. regia bark chewing sticks as an oral hygiene material. Antifungal, antibacterial and antioxidant activities of this plant have also been described (Isanga et al., 2007; Miraliakbari \& Shahidi, 2008; Amaral et al., 2003). The health benefits of walnuts are usually attributed to their chemical composition. Walnuts are good source of essential fatty acids and tocopherols (Amaral et al., 2005). In case of Saudi Arabia many women used (J. regia) for cleaning teeth, it was thought to make teeth look whiter and shiny. The women also used it as a dye for coloring lips, which would get red-brown coloration, but this habit has become less common in the new generation (Abu Taha \& Al-wadaan, 2011).

In addition, walnuts have other components that may be beneficial for health including plant protein, dietary fiber, melatonin (Reiter et al., 2005), plant sterols (Amaral et al., 2005), folate, tannins and polyphenols (Li et al., 2006). Walnuts possess a high content of $\alpha$-tocopherol, a vitamin $E$ family compound, which has antioxidant activity, mainly in the prevention of lipid oxidation process (Koksak et al., 2006). Plant-derived products with phenolics and polyphenolic components.can also be used as antimicrobial agents. Despite the wide use of walnut, the plant has not received much attention and has not been intensively studied. Therefore, the present work is aimed to screen the antimicrobial activities and compounds of two different origins of the bark extracts and to highlight their potential and ability of producing several compounds of industrial importance.

\section{Materials and Methods}

\subsection{Sample Collection}

The bark samples were collected from two different origins; one from Jalalabad area in Afghanistan as natural source (sample 1 code used as MHO) (Figure 2). The other sample as commercial source from a local store in Riyadh, Saudi Arabia (the sample 2 code used as MHC (Figure 3).

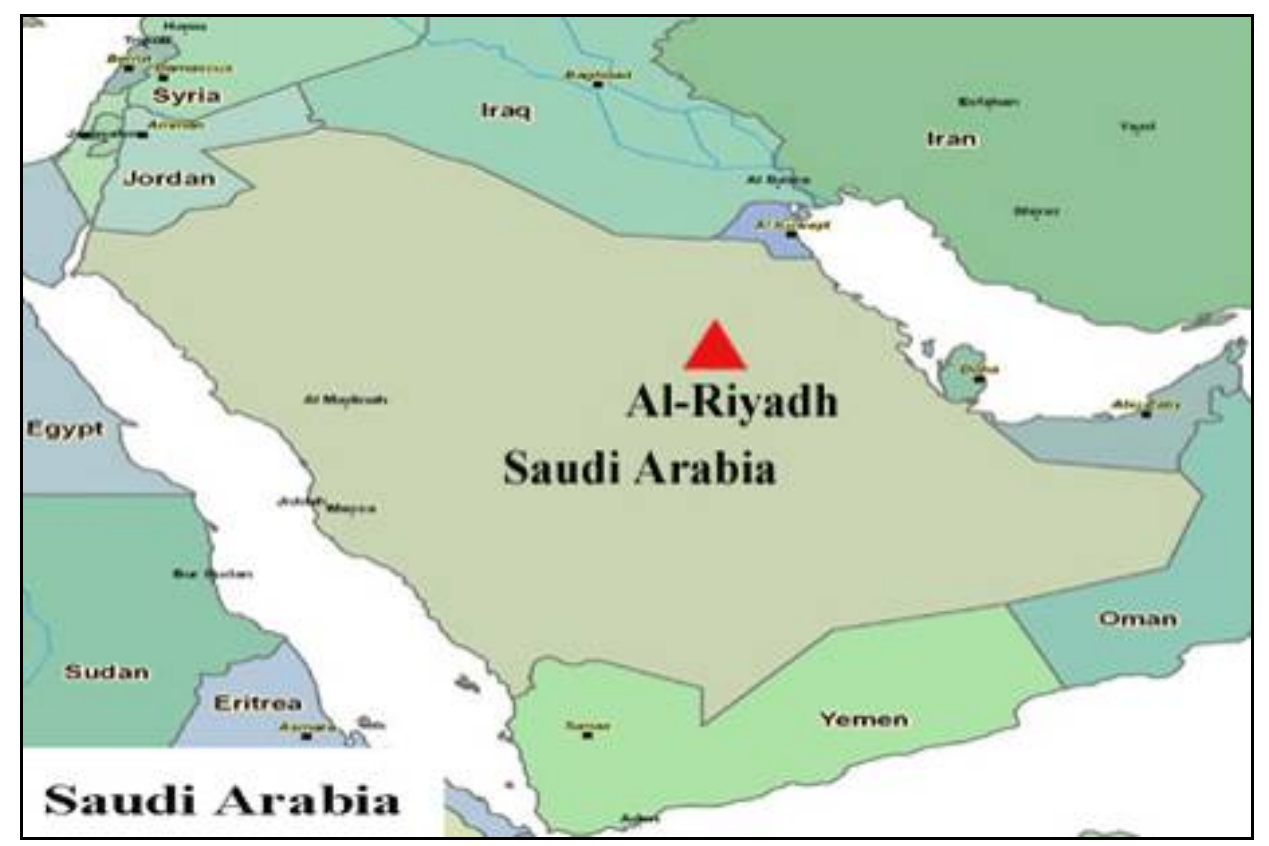

Figure 3. The map of Saudi Arabia showing the sample 1 (code MHC) collection region Riyadh (red arrow) 


\subsection{Sample Preparation and Compounds Extraction}

For the extraction, two crushed and semi-powdered samples $(500 \mathrm{~g})$ were soaked into $1000 \mathrm{ml}$ methanol (purity 99.5\%) in two separate conical flasks. All the flasks were capped tightly with aluminum foil and tape (Schott, Duran, $2000 \mathrm{ml}$ ). The mixtures were allowed to soak for one week at room temperature (about $30^{\circ} \mathrm{C}$ ) for proper extraction of the samples. The extract was filtered using filter paper and dried for three days at $50^{\circ} \mathrm{C}$ in a drier until all the solvent was evaporated in a glass beaker. The antimicrobial activities of the two extracts were evaluated using agar well diffusion assay against seven human pathogenic microorganisms.

\subsection{Microorganisms Used in the Study}

Human pathogenic microorganisms used in this study were obtained from the Laboratory of Microbiology located in the Department of Botany and Microbiology, Faculty of Science, King Saud University, Saudi Arabia. The microorganisms tested in the study as follows: Gram-positive bacteria: B. subtilis ATCC 6633 and S. aureus ATCC 25923; Gram-negative bacteria: S. suis ATCC 13076, P. aeruginosa ATCC 27583; E. coli ATCC 25922; S. sonnei ATCC 11060 and one human pathogenic fungus: C. albicans ATCC 10231. Methanol and sterile water were used as positive and negative control, respectively.

\subsection{Preparation of Microorganisms and Antimicrobial Activity Assay}

The pathogens were cultured by transferring a loop full of the microorganisms into tubes containing $9 \mathrm{ml}$ of Nutrient broth and incubated at $37^{\circ} \mathrm{C}$ for $24 \mathrm{~h}$. The overnight cultures were used for the antimicrobial activities of the extracts investigated in this study. In addition, Mueller Hinton (MH) agar was prepared and poured into Petri dishes and allowed to cool down and a loop full of each microorganism was inoculated on the surface of a separate MH agar plate. The antimicrobial activity was determined by the agar-well diffusion method (Table 1). Subsequently agar wells were formed on the surface of the agar using sterile plastic straw (6 $\mathrm{mm}$ in diameter), then $0.1 \mathrm{ml}$ of each extract was pipetted into the wells. The plates were then incubated at $37^{\circ} \mathrm{C}$ for $24 \mathrm{~h}$. After this period, it was possible to observe zones of inhibition around the agar wells (Figure 4) demonstrating the effects of the bark's extracts. The diameters of the zones were measured using $1 \mathrm{~mm}$ ruler. The difference in the size of inhibition zone between the two samples is shown in the diagram in (Figure 5).

Table 1. The antibacterial activity of crude extract from the two different $J$. regia barks

\begin{tabular}{|c|c|c|c|c|c|c|c|}
\hline \multirow[b]{3}{*}{$\begin{array}{c}\text { Extract } \\
\text { Code }\end{array}$} & \multicolumn{7}{|c|}{ Pathogenic microorganism } \\
\hline & \multicolumn{2}{|c|}{ Gram positive bacteria } & \multicolumn{4}{|c|}{ Gram negative bacteria } & \multirow{2}{*}{$\begin{array}{c}\text { Yeast } \\
\text { C. albicans } \\
\text { ATCC } \\
10231\end{array}$} \\
\hline & $\begin{array}{l}\text { S. suis } \\
\text { ATCC } \\
13076\end{array}$ & $\begin{array}{l}P . \\
\text { aeruginosa } \\
\text { ATCC } \\
27583\end{array}$ & $\begin{array}{l}\text { E. coli } \\
\text { ATCC } \\
2592\end{array}$ & $\begin{array}{l}\text { S. } \\
\text { sonnei } \\
\text { ATCC } \\
11060\end{array}$ & $\begin{array}{l}\text { B. subtilis } \\
\text { ATCC } \\
6633\end{array}$ & $\begin{array}{l}\text { S. aureus } \\
\text { ATCC } \\
13076\end{array}$ & \\
\hline MHO & $\begin{array}{c}20 \mathrm{~mm} \\
(++)\end{array}$ & $20 \mathrm{~mm}(++)$ & $\begin{array}{c}13 \mathrm{~mm} \\
(++)\end{array}$ & $\begin{array}{c}28 \mathrm{~mm} \\
(+++)\end{array}$ & $15 \mathrm{~mm}(++)$ & $\begin{array}{c}30 \mathrm{~mm} \\
(+++)\end{array}$ & $\begin{array}{c}25 \mathrm{~mm} \\
(+++)\end{array}$ \\
\hline MHC & $\begin{array}{c}17 \mathrm{~mm} \\
(++)\end{array}$ & $\begin{array}{c}25 \mathrm{~mm} \\
(+++)\end{array}$ & $\begin{array}{c}15 \mathrm{~mm} \\
(++)\end{array}$ & $\begin{array}{c}28 \mathrm{~mm} \\
(+++)\end{array}$ & $16 \mathrm{~mm}(++)$ & $\begin{array}{c}25 \mathrm{~mm} \\
(+++)\end{array}$ & $\begin{array}{c}25 \mathrm{~mm} \\
(+++)\end{array}$ \\
\hline
\end{tabular}



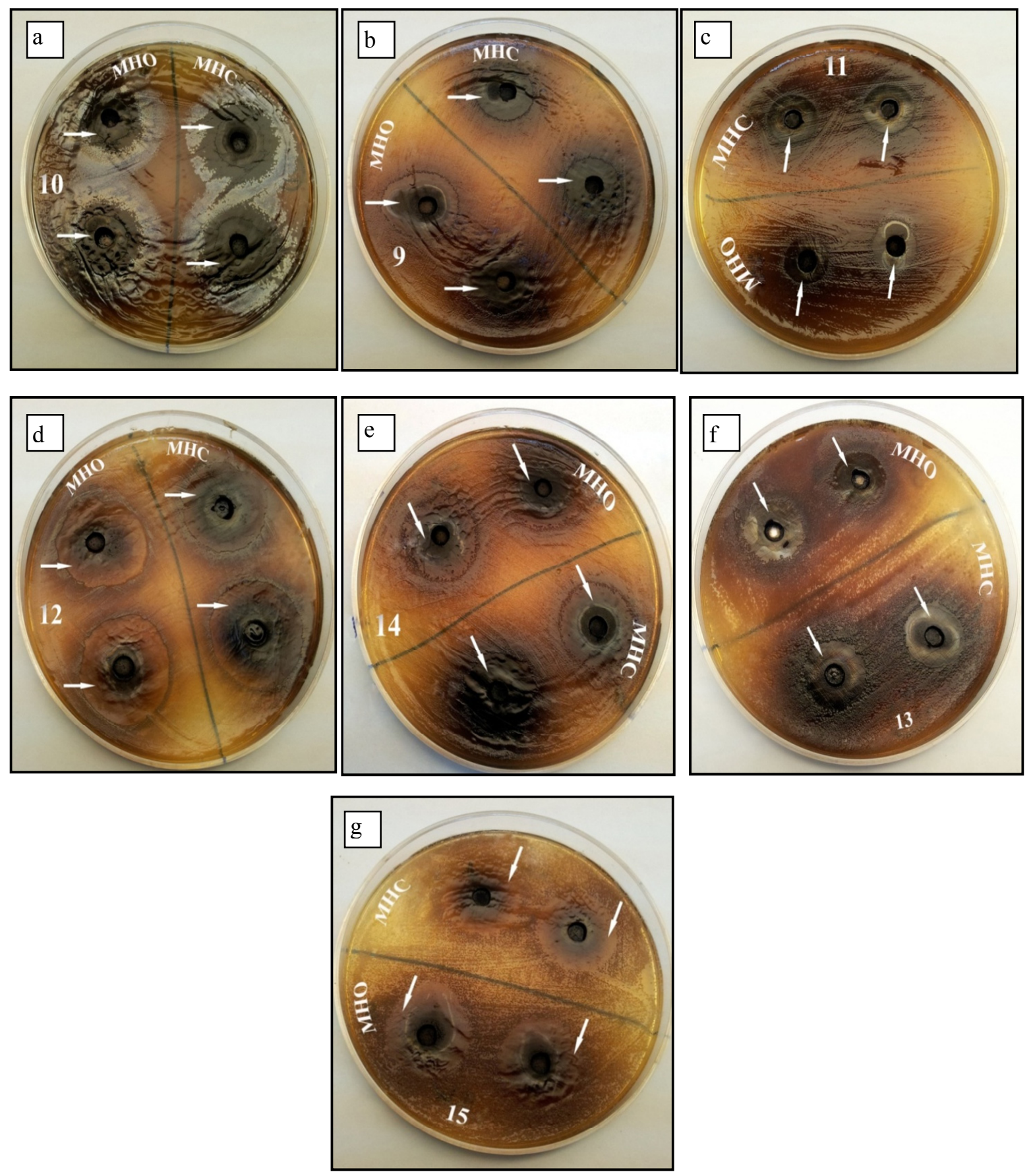

Figure 4. Screening by agar well diffusion method showing the inhibition zone caused by the antagonistic ability of the two extracts (MHO and MHC) bioactive compound against: a. S. suis, b. P. aeruginosa, c. E. coli, d. S. sonnei, e. B. subtilis, f. S. aureus and g. C.albicans 


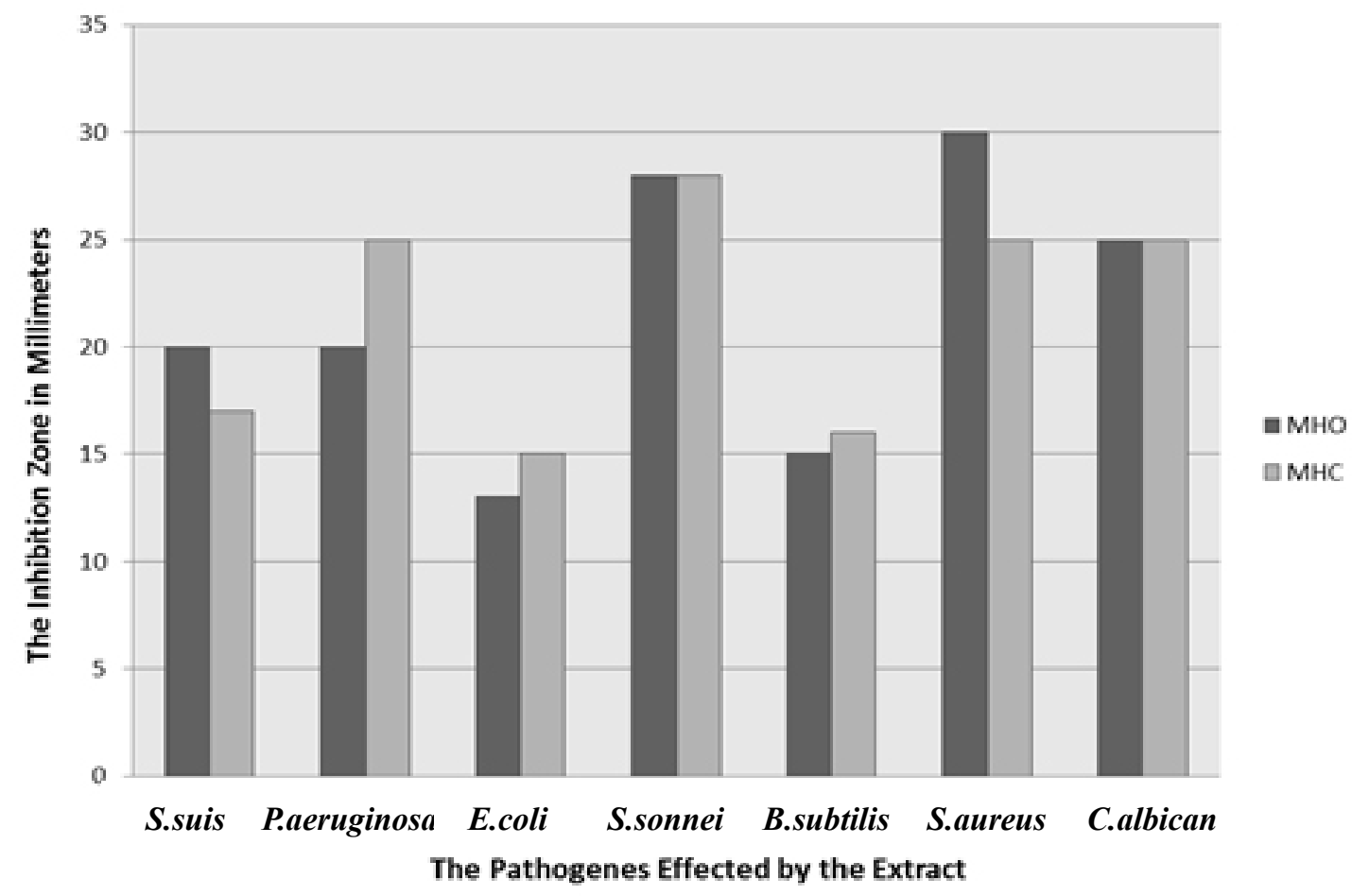

Figure 5. Diagram comparing the antimicrobial activity from the two extracts against seven human pathogens

\subsection{Gas Chromatography (GC)-Mass Spectroscopy (MS) Analysis}

Gas chromatography-mass spectroscopy (GC-MS) analysis of crude extract was performed to identify the antimicrobial compound in the extract. Interpretation was conducted using the database of National Institute Standard and Technology (NIST) having more than 62,000 patterns. The spectrum of the unknown compounds was compared with the spectrum of the known compounds stored in the NIST library. The compounds name, molecular weight and structure of the compounds of the test materials were obtained. The identification of the compounds was done by injecting $1.0 \mu \mathrm{l}$ of sample into a RT X-5 column (30 X $0.32 \mathrm{~nm}$ ) of GC-MS model (Perkin Elmer, Clarus 500, USA) and helium ( $3 \mathrm{ml} / \mathrm{min})$ was used as a carrier gas. The following temperature gradient program was used $\left(75^{\circ} \mathrm{C}\right.$ for 2 min followed by an increase from 75 to $175^{\circ} \mathrm{C}$ at a rate $0 f 50^{\circ} \mathrm{C}$ per min and finally $7 \mathrm{~min}$ at $175^{\circ} \mathrm{C}$ ). The $\mathrm{m} / \mathrm{z}$ peaks representing mass to charge ratio characteristics of the antimicrobial fractions were compared with those in the mass spectrum library of the corresponding organic compounds (Pandey et al., 2010). The chemical compounds of the extracts were analyzed in the central laboratory of King Saud University, Riyadh, Saudi Arabia. Identification of the chemical constituents of extracts were performed using Perkin Elmer (Clarus 500, USA) gas chromatography coupled with (Clarus 500, USA) mass spectro-meter (MS). Identification of the constituents was based on comparison of the retention times with those of authentic samples, comparing their linear retention indices relative to the series of n-hydrocarbons, and on computer matching against commercial (NIST 98 and ADAMS) and homemade library mass spectra built up from pure substances and components of known oils and MS literature data as previously reported by Hajlaoui et al. (2009). Moreover, the molecular weights of all the identified substances were confirmed by GC-MS, using $\mathrm{MeOH}$ as CI ionizing.

\section{Results and Discussion}

\subsection{Antagonistic Activity of the Extracts against Pathogenic Microbes}

The two $J$. regia tree bark extracts were screened and compared for their potential as a source of antibiotics active against human pathogenic microbes. The formation of inhibition zone around the agar well against pathogenic strains was indicative of the presence of some antimicrobial compound of each extract. Both extracts were tested for their ability to produce inhibitory substances against seven test microorganisms. The test microorganisms included two Gram positive bacteria: S. aureus ATCC 25923 and B. subtilis ATCC 6633 
(Gislene et al., 2000), four Gram negative bacteria: E. coli ATCC 25922 (Ali-Shtayah et al., 1999), P. aeruginosa ATCC 27853 (Emira et al., 2011), S. suis ATCC 13076 and S. sonnei ATCC 11060 and one yeast which was C. albicans ATCC 10231 (Upadhyay et al., 2010; Ahmad et al., 1973). In our study, (Table 1 \& Figure 5), both extracts were shown to have a very strong antimicrobial activity against the test organisms with a little variation. Both extracts contained antibacterial substances against Gram negative and Gram positive bacteria used in the test. Three of the pathogenic microorganisms were inhibited greatly by both extracts which were S. sonnei ATCC 11060; S. aureus ATCC 13076 and C. albicans ATCC 10231. Both extracts showed moderate activity against S. suis ATCC 13076; P. aeruginosa ATCC 27583; E. coli ATCC 2592 and B. subtilis ATCC 6633. The extract of MHO appeared to affect S. suis ATCC 13076 and S. aureus ATCC 25923 greater than the effect from the extract of MHC. The extract of MHC effects $P$. aeruginosa ATCC 27853 much greater then MHO which is shown clearly in Table 1 and Figure 4. The inhibition zone of sample MHO against $S$. suis ATCC 13076 was $20 \mathrm{~mm}$ and against $S$. aureus ATCC $2592330 \mathrm{~mm}$ while from the sample MHC, the zone againt $S$. suis was $17 \mathrm{~mm}$ and from $S$. aureus was $25 \mathrm{~mm}$. Further, in this study, the inhibition zone against $P$. aeruginosa ATCC 27853 of the sample MHO extract was $20 \mathrm{~mm}$ while for MHC it was $25 \mathrm{~mm}$. Methanol and sterile water were used as positive and negative control, respectively.

\subsection{Chemical Compositions Comparison in Both Extracts}

The tentative chemical compositions of two crude extracts were analyzed using GC-MS (Figures $6 \& 7$ ). The percentages of major components of the extracts are given in Table 2 and 3, which demonstrated an interesting concoction of compounds with significant antimicrobial activity. According to the results from the GC-MS (Tables $2 \& 3$ ), it is clear that some compounds were present in both extracts which were: cyclobutanol (91.7\%) (Alaaddin et al., 2001); cyclopropyl carbinol (84.5\%) (Lumir et al., 2008); alanine (80.9\%) (Li et al., 2012); (r)-(-)-2-amino-1-propanol (80.5\%); 4h-pyran-4-one,2,3-dihydro-3,-dihydroxy-6-methyl (92.5\%) reported as an odor compound (Preininger et al., 2009) and based on previous studies, several important biological activities of this compound were observed by several researchers such as anti-mutagenic activity agent against arylamine and 2-acetoxyacetylaminofluorene (2AAAF)-induced DNA damage in Chinese hamster ovary cells, (Berhow et al., 2000), anti-alpha-glucosidase activity in patients with diabetes mellitus, (Quan et al., 2003), reactive oxygen scavenging activity agent (Takara et al., 2007) and also anti-tumour activity (Ban et al., 2007); 1,3-dioxolane-4-methanol,2,2-dimethyl (88.6\%) reported as antimicrobial agent (Daniela et al., 2009); pyrimidine-2,4(1h,3h)-dione,5-amino-6-nitroso (82.6\%); butanenitrile,2,3dioxo,dioxime,o,o-diacetyl (805\%); 1,6,3,4-dianhydro-2-deoxy-beta-d-lyxo-hexopyranose (81.3\%); 2-heptanamine,5-methyl $\quad(82.1 \%) \quad$ and benzaldehyde, 4-ethoxy (80.2\%) (Table 2) in which some of them were reported to be antimicrobial agents (Ahmedzade et al., 2003).

Other compounds appeared separately in each of the two extracts. The following compounds were found in the extract MHO but not in MHC: ethanamine,2-propoxy (91.2\%); 2-isopropoxyethylamine (91\%); (r)-(-)-2,2-dimethyl-1,3-dioxolane-4-methanol (87.5\%); glycerin (82.7\%); 3,4-furandiol, tetrahydro-,cis (85.8\%); 1-octadecanamin,n-methyl (80.9\%); (s)-(+)-1-cyclohexylethylamine $(80 \%)$; eicosanoic acid $(81.2 \%)$ and pentadecanoic acid (81\%). In case of the extract MHC, the compound in the following list were present: 2-hydroxy-3,5-dimethylcyclopent-2-en-1-one (85.8\%); 2-undecene,(e) (89.1\%); acetic acid, trifluoro-, decyl ester (86.6\%); 4-tridecene,(z) (89.3\%), 4-tetradecene,(z) (88.5\%), d-glycero-d-tallo-heptose (80.9\%); 11-tridecen-1-ol (89.3), hexadecanal (89.3\%) and 1,3-dioxolane,2,4,5-trimethyl (92.9\%), which some were identified as antimicrobial agents. In our GC-MS data (Tables $2 \& 3$ ), it is visible that the main compound with the highest percentage for MHO was cyclobutanol (91.7\%), while for MHC it was 1,3-dioxolane,2,4,5-trimethyl $(92.9 \%)$. From our data it was found that the cyclobutanol (91.7\%) was present in both extract in high percentage and was reported as antimicrobial compound (Ahmedzade et al., 2003; Anastasia et al., 2008; Alaaddin et al., 2001).

Although in both extracts several compounds varied which could be because of the two different origins, nature of the climate, soil's $\mathrm{pH}$, the temperature and the nutrition sources. In this preliminary research our findings showed the similarities of bioactivity against several human pathogenic bacteria. Later based on GC-MS analysis we have concluded that in our two bark extracts there were similarities and dissimilarities in the percentages of several compounds. We have also concluded that these findings will support the search for further novel compounds in plant extracts that could be responsible for the inhibition of the growth of human pathogenic microbes. 


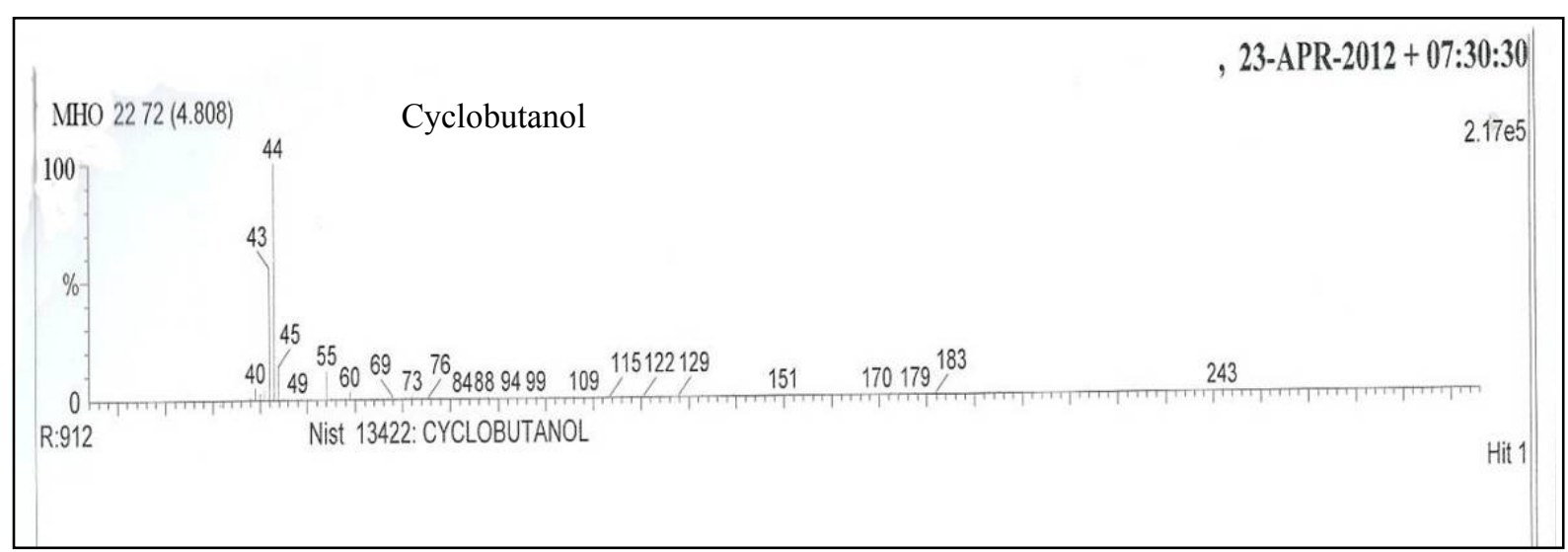

Figure 6. Mass spectrum of $J$. regia methanolic extract for cyclobutanol which appeared to have the highest percentage in both sample MHO and MHC

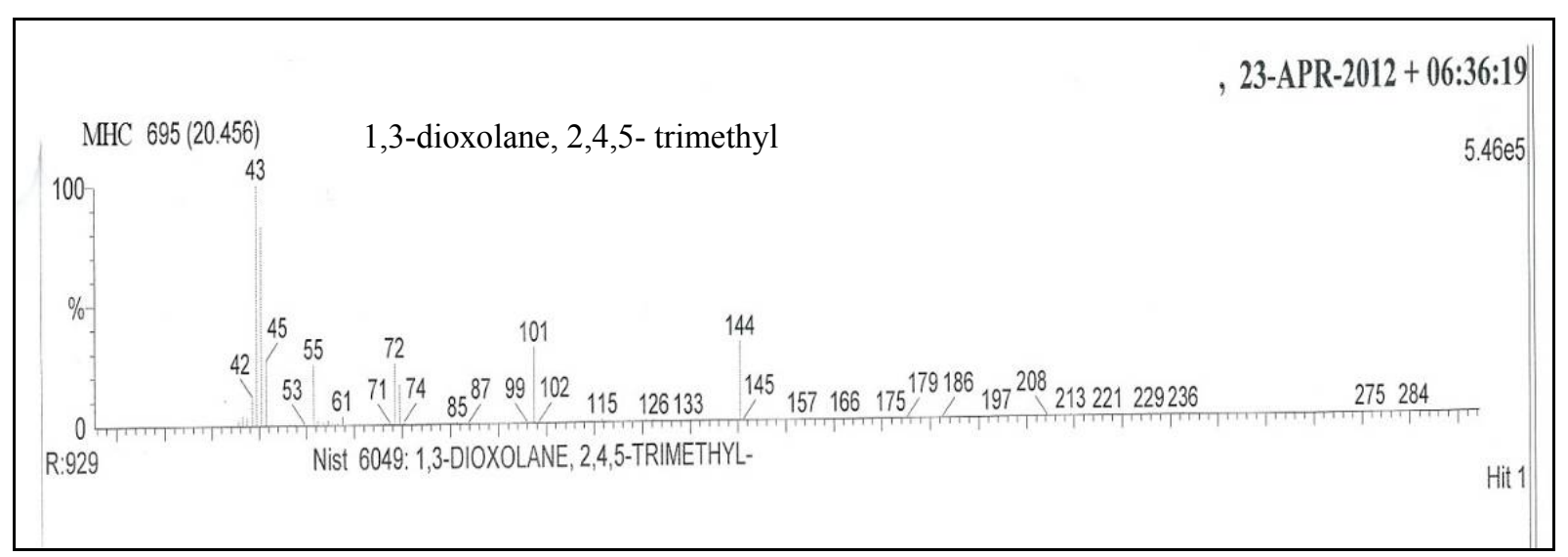

Figure 7. Mass spectrum of $J$. regia methanolic extract for 1,3-dioxolane,2,4,5- trimethyl which appeared to be the highest percentage present in the bark sample 2 collected from Saudi Arabia (MHC)

Table 2. GC-MS analysis for the methanolic bark extract of $J$. regia for similar compounds found in MHO and MHC

\begin{tabular}{ll}
\hline Compound name & $\begin{array}{l}\text { Percentage of compound } \\
\text { in whole extract }\end{array}$ \\
\hline cyclobutanol & $91.7 \%$ \\
4h-pyran-4-one,2,3-dihydro-3,-dihydroxy-6-methyl & $89.8 \%$ \\
1,3-dioxolane-4-methanol,2,2-dimethyl & $88.6 \%$ \\
1,6,3,4-dianhydro-2-deoxy-beta-d-lyxo-hexopyranose & $87.5 \%$ \\
Cycloprop yl carbinol & $84.5 \%$ \\
2-heptanamine,5-methyl- & $82.1 \%$ \\
pyrimidine-2,4(1h,3h)-dione,5-amino-6-nitroso & $81.5 \%$ \\
alanine & $80.9 \%$ \\
butanenitrile,2,3-dioxo-,dioxime,o,o-diacetyl & $80.7 \%$ \\
(r)-(-)-2-amino-1-propanol & $80.5 \%$ \\
benzaldehyde,4-ethoxy & $80.3 \%$ \\
\hline
\end{tabular}


Table 3. GC-MS analysis for the methanolic bark extract of J. regia for dissimilar compounds found in MHO and $\mathrm{MHC}$

\begin{tabular}{|c|c|c|c|}
\hline \multicolumn{2}{|l|}{ MHO } & \multicolumn{2}{|l|}{ MHC } \\
\hline Compound name & $\begin{array}{l}\text { Percentage } \\
\text { of } \\
\text { compound } \\
\text { in whole } \\
\text { extract }\end{array}$ & Compound name & $\begin{array}{l}\text { Percentage } \\
\text { of } \\
\text { compound } \\
\text { in whole } \\
\text { extract }\end{array}$ \\
\hline ethanamine,2-propoxy & $91.2 \%$ & 1,3-dioxolane,2,4,5-trimethyl & $92.9 \%$ \\
\hline 2-isopropoxyethylamine & $91 \%$ & 11-tridecen-1-ol & $89.3 \%$ \\
\hline $\begin{array}{l}\text { (r)-(-)-2,2-dimethyl-1,3-dioxolane } \\
\text {-4-methanol }\end{array}$ & $87.5 \%$ & hexadecanal & $89.3 \%$ \\
\hline 3,4-furandiol, tetrahydro-,cis & $85.8 \%$ & 4-tridecene, $(\mathrm{z})$ & $89.3 \%$ \\
\hline glycerin & $82.7 \%$ & 2-undecene,(e) & $89.1 \%$ \\
\hline eicosanoic acid & $81.2 \%$ & 4-tetradecene, $(\mathrm{z})$ & $88.5 \%$ \\
\hline pentadecanoic acid & $81 \%$ & acetic acid, trifluoro-, decyl ester & $86.6 \%$ \\
\hline 1-octadecanamin,n-methyl & $80.9 \%$ & $\begin{array}{l}\text { 2-hydroxy-3,5-dimethylcyclopent } \\
\text {-2-en-1-one }\end{array}$ & $85 \%$ \\
\hline (s)-(+)-1-cyclohexylethylamine & $80 \%$ & d-glycero-d-tallo-heptose & $80.9 \%$ \\
\hline
\end{tabular}

\section{Conclusion}

The bark extract in both samples showed strong activities against almost all the human pathogenic microorganisms. Furthermore, the GC-MS results of the purified crude extract indicated that the main component in the crude extract for bark sample 1 (MHO) was cyclobutanol (91.7\%) and for bark sample 2 (MHC) was 1, 3-dioxolane, 2, 4, 5-trimethyl (92.9\%). In both extracts cyclobutanol was present in high percentage (91.7\%). Further, 4h-pyran-4-one,2,3-dihydro-3,-dihydroxy-6-methyl; 1,3-dioxolane-4-methanol,2,2-dimethyl; 1,6,3,4-dianhydro-2-deoxy-beta-d-lyxo-hexopyranose; cyclopropyl carbinol; 2-heptanamine,5-methyl-; pyrimidine-2,4(1h,3h)-dione,5-amino-6-nitroso; alanine; butanenitrile,2,3-dioxo-,dioxime,o,o-diacetyl; (r)-(-)-2-amino-1-propanol and benzaldehyde,4-ethoxy were present in both bark extracts as $80-89 \%$. Therefore, further study on the step by step chemical purification of the crude bark extract will improve our preliminary findings as antibacterial activities for two walnut barks sample collected from Saudi Arabia and Afghanistan.

\section{Acknowledgement}

This research project was supported by a grant from the "Research Center of Female Scientific and Medical Colleges", Deanship of Scientific Research, King Saud University.

\section{References}

Ahmad, S., Mukhtar, W. A., \& Bukhari, A. Q. S. (1973). Fungistatic Action of Juglans. Antimicrobial Agents Chemotherapy, 3, 436-438. http://dx.doi.org/10.1128/AAC.3.3.436

Ahmedzade, M., Cukurovali, A., \& Koparir, M. (2003). Synthesis and antimicrobial activity of some new 1, 1, 3 -trisubstituted cyclobutane containing thiazoles, succinimide and phthalimide derivatives. Journal of the Chemical Society of Pakistan, 25, 51-55.

Alaaddin, C., Ibrahim, Y., \& Habibe, O. (2001). Antimicrobial activity studies of the metal complexes derived from substituted cyclobutane substituted thiazole Schiff base ligands. Transition Metal Chemistry, 26, 619-624. http://dx.doi.org/10.1023/A:1012006404144

Ali-Shtayeh, M. S., \& Abu Ghdeib, S. I. (1999). Antifungal activity of plant extracts against dermatophytes. Mycoses, 42, 665-772. http://dx.doi.org/10.1046/j.1439-0507.1999.00499.x

Almeida, I. F., Fernandes, E., Lima, J. L. F. C., Costa, P. C., \& Bahia, M. F. (2008). A research on strong scavenge of pro-oxidant reactive of leaf extracts in walnut (Juglans regia) species. Food Chemistry, 106, 1014-1020. http://dx.doi.org/10.1016/j.foodchem.2007.07.017 
Amaral, J. S., Alves, M., Seabra, R., \& Oliveira, B. (2005). Vitamin E composition of walnuts (Juglans regia L.): a 3-year comparative study of different cultivars. Journal of Agricultural \& Food Chemistry, 53, 5467-5472. http://dx.doi.org/10.1021/jf050342u

Amaral, J. S., Casal, S., Pereira, J., Seabra, R., \& Oliveira, B. (2003). Determination of sterol and fatty acid compositions, oxidative stability and nutritional value of six walnut (Juglans regia L.) cultivars grown in Portugal. Journal of Agricultural \& Food Chemistry, 51, 7698-7702. http://dx.doi.org/10.1021/jf030451d

Anastasia, S., Vladimir, V. P., Lumir, O. H., \& Valery, M. D. (2008). Cyclobutane-Containing Alkaloids: Origin, Synthesis, and Biological Activities. The Open Medicinal Chemistry Journal, 2, 26-37. http://dx.doi.org/10.2174/1874104500802010026

Ban, J. O., Hwang, I. G., Kim ,T. M., Hwang, B. Y., Lee, U. S., Jeong, H. S., ... Hong. J. T. (2007). Anti-proliferate and pro-apoptotic effects of 2,3-dihydro-3,5-dihydroxy-6-methyl-4H-pyranone through inactivation of NF-KB in human colon cancer cells. Archives of Pharmacal Research, 30(11), 1455-1463. http://dx.doi.org/10.1007/BF02977371

Berhow, M. A. Wagner, E. D., Vaughn, S. F. \& Plewa, M. J. (2000). Characterization and antimutagenic activity of soybean saponins. Mutation Research/Fundamental \& Molecular Mechanisms of Mutagenesis, 448(1), 11-22. http://dx.doi.org/10.1016/S0027-5107(99)00225-0

Daniela, I. B., Iva, T. T, Iva,V. T. \& Hristo, M. N. (2009). Antibacterial Study of the Medium Chain Fatty Acids and Their 1-Monoglycerides Individual Effects and Synergistic Relationships. Polish Journal of Microbiology, 1, 43-47.

Emira, N., Mejdi, S. N. T., Hafedh, H., Riadh, K., Eulogio, V., \& Amina, B. (2011). Antibacterial, anticandidal and antioxidant activities of Salvadora persica and Juglans regia L. extracts. Journal of Medicinal Plants Research, 5(17), 4138-4146.

Evans, C. E., Banso, A., \& Samuel, O. A. (2002). Efficacy of some nupe medicinal plants against Salmonella typhi: an in vitro study. Journal of Ethnopharmacology, 80, 21-24. http://dx.doi.org/10.1016/S0378-8741(01)00378-6

Fernandez, 1. J., Aleta, N., \& Ricardo, A. (2003). Walnut (Juglans regia L.) genetic resources (pp. 25-28). European Forest Genetic Resources Programme. International plant Genetic resources Institute.

Gislene, G. F. N., Juliana, L., Paulo, C. F., \& Giuliana, L. S. (2000). Antibacterial activity of plant extracts and phytochemicals on antibioticresistant Bacteria. Brazilian Journal of Microbiology, 31, 247-256.

Isanga, J., \& Zhang, G. N. (2007). Biological active components and nutraceuticals in peanuts and related products: Review. Food Reviews International, 23, 123-140. http://dx.doi.org/10.1080/87559120701224956

Koksak, A., Artik, N., Simsek, A., \& Gunes, N. (2006). Nutrient composition of hazelnut (Corylus avellana L.) $\begin{array}{llll}\text { varieties cultivated in Turkey. Food Chemistry, 99, 509-515. } & \text {. }\end{array}$ http://dx.doi.org/10.1016/j.foodchem.2005.08.013

Li, L., Tsao, R., Yang, R., Liu, C., Zhu, H., \& Young, J. C. (2006). Polyphenolic profiles and antioxidant activities of heartnut (Juglans ailanthifolia var. cordiformis) and Persian walnut (Juglans regia L.). Journal of Agricultural \& Food Chemistry, 54, 8033-8040. http://dx.doi.org/10.1021/jf0612171

Li, C., Wen-Dee, C., Wei-Chiuan, C., Hui-Huang, C., Yao-Wen, H., Wei-Jung, C. \& Shih-Bin, L. (2012). Influence of alanine uptake on Staphylococcus aureus surface charge and its susceptibility to two cationic antibacterial agents, nisin and low molecular weight chitosan. Food Chemistry, 135(4), 2397-403. http://dx.doi.org/10.1016/j.foodchem.2012.06.122

Lumir, O. H, Paulina, G., \& Valery, M. D. (2008). Identification of cyclopropyl fatty acids in walnut (Juglans regia 1.) Oil. Biomed Pap Med Fac Univ Palacky Olomouc Czech Republic, 152(1), 41-45. http://dx.doi.org/10.5507/bp.2008.006

McGranahan, G., \& Leslie, C. (1990). Walnuts (Juglans). In J. N. Moore, \& J. R. Balington (Eds.), Genetic Resources of Temperate Fruit and Nut Crops (pp. 907-951). The Netherlands: ISHS, Wageningen.

McGranahan, G. H., Charles, A., Leslie, C. A., Philips, H. A., \& Dandaker, A., (1998). Walnut propagation. In D. Ramos (Ed.), Walnut Production Manual (pp. 71-83). University of California, DANR Publications.

Miraliakbari, H., \& Shahidi, F. (2008). Oxidative stability of tree nut oils. Journal of Agricultural and Food Chemistry, 56, 4751-4759. http://dx.doi.org/10.1021/jf8000982 
Nael Abu Taha, N., \& Al-wadaan, M. A. (2011). Utility and importance of walnut, Juglans regia Linn. African Journal of Microbiology Research, 5(32), 5796-5805.

Oliveira, I., Sousa, A., \& Isabel, C. (2008). Total phenols, antioxidant potential and antimicrobial activity of walnut (Juglans regia L.) green husks. Food Chemistry. Toxicol.

Pandey, A., Milind, M., \& Naik Dubey, S. K. (2010). Organic metabolites produced by Vibrio parahaemolyticus strain An3 isolated from Goan mullet inhibit bacterial fish pathogens. Goa, India. African Journal of Biotechnology, 9(42), 7134-7140.

Pereira, J. A., Oliveira, I., Sousa, A., Valentao, P., Andrade, P. B., Ferreira, I. C. F. R., ... Estevinho, L. (2007). Food Chemistry. Toxicol., 45(11), 2287-2295. http://dx.doi.org/10.1016/j.fct.2007.06.004

Preininger, M., Gimelfarb, L., Li, H. C., Dias, B. E., Fahmy, F., \& White, J. (2009). Identification of dihydromaltol (2,3-dihydro-5-hydroxy-6-methyl-4H-pyran-4-one) in Ryazhenka Kefir and comparative sensory impact assessment of related cycloenolones. Journal of Agricultural Food Chemistry, 57(21), 9902-9908. http://dx.doi.org/10.1021/jf901569f

Proestos, C., Chorianopoulos, N., Nychas, G. J. E., \& Komaitis, M. (2005). RPHPLC analysis of the phenolic compounds of plant extracts. Investigation of their antioxidant capacity and antimicrobial activity. Journal of Agricultural and Food Chemistry, 53, 1190-1195. http://dx.doi.org/10.1021/jf040083t

Quan, J., Yin, X., Jin, M., \& Shen, M. (2003). Study on the inhibition of alpha-glucosidase by soyasaponins. 26(9), 654-656.

Rauha, J. P., Remes, S., Heinonen, M., Hopia, A., Kahkonen, M., Kujala, T., ... Vuorela, P. (2000). Antimicrobial effects of Finnish plant extracts containing flavonoids and other phenolic compounds. International Journal of Food Microbiology, 56, 3-12. http://dx.doi.org/10.1016/S0168-1605(00)00218-X

Reiter, R. J., Manchester, L. C., Dun, X., \& Tan, M. D. (2005). Melatonin in walnuts: influence on levels of melatonin and total antioxidant capacity of blood. Nutrition, 21, 920-924. http://dx.doi.org/10.1016/j.nut.2005.02.005

Takara, K., Otsuka, K., Wada, K., Iwasaki, H., \& Yamashita, M. (2007). 1,1-diphenyl-2-picrylhydrazyl radical scavenging activity and tyrosinase inhibitory effects of constituents of sugarcane molasses. Bioscience Biotechnology \& Biochemistry, 71(1), 183-191. http://dx.doi.org/10.1271/bbb.60432

Upadhyay, V., Kambhoja, S., \& Harshaleena, K. (2010). Antifungal activity and preliminary phytochemical analysis of stem bark extracts of Juglans regia linn. International Journal of Pharmaceutical \& Biological Archive, 1, 442-447. 